\title{
ESTRATEGIAS EMPRESARIALES PERUANAS EN LA PRIMERA GLOBALIZACIÓN: PARTICIPACIÓN TEMPRANA EN EXPOSICIONES INTERNACIONALES
}

\author{
LIZARDO A. SEINER \\ - Profesor de Globalización: Apertura y Tendencias \\ Área Académica de Administración, UPC
}

\section{RESUMEN}

Las Exposiciones Universales (EXPO), datan de 1850 y representan un potente evento de carácter internacional para alentar el progreso, la promoción del desarrollo y una expresión visible del proceso de globalización. La prensa local criticó fuertemente que el Perú no asistiera a la EXPO 2015; cabe preguntarse: ¿fue esta la primera vez que el país no participó? El presente trabajo se interroga sobre la relevancia de las EXPO, analizando sus aportes, desde una perspectiva histórica y señalando su utilidad para agregar valor a los negocios. Dada su resonancia para efectos de posicionamiento de una imagen nacional, se ve como necesario revisar las relaciones empresaEstado en el marco de las políticas comerciales.

Palabras clave: Exposiciones universales, globalización, políticas comerciales.

\section{ABSTRACT}

Universal Exhibitions (EXPO), date from 1850, and represent a powerful international event to encourage progress, the promotion of development and a visible expression of the process of globalization. In Peru, the press severely criticized that the nation did not attend to the 2015 EXPO. It is hence worth asking if this was first time the country did not participate in one of these events. This essay, in this context addresses. The relevance of the EXPO, as it analyses their contributions, to the above from a historical perspective, and points out its usefulness to adding value in businesses. Given EXPO resonance, for the purpose of positioning a national image, it is also seen as necessary to review, in ending, the relationships between The Government and private firms within the framework of commercial policies.

Keywords: World's fair, globalization, commercial politics.

La última Exposición Universal (genéricamente conocida como, EXPO), que tuvo lugar entre mayo y octubre de 2015 en la ciudad de Milán, atrajo en ese medio año 20 millones de visitantes a las distintas exhibiciones simultáneas con las que alrededor de 150 países de todo el mundo mostraron entusiasmados diversas dimensiones de su identidad nacional y de sus logros tecnológicos (EXPO
Milano 2015, s. f.). En términos generales, la EXPO es un evento mundial promovido por la Oficina Internacional de Exposiciones, en el que una ciudad elegida como sede, de entre varias candidatas, organiza una convocatoria para la concurrencia de países, con el objetivo de mostrar los avances de cada uno en distintos ámbitos de la economía, la cultura y la tecnología.

Encuentros de este tipo no son nuevos: son la continuación de las antiguas EXPO, eventos que se desarrollaron en Europa desde inicios de la década de 1850, conocidos también con posteridad como World Fairs. Sea una denominación u otra, cada EXPO representa una potente convocatoria de carácter internacional que se considera, hechas las distinciones, a la par de un campeonato mundial de fútbol o de los mismos Juegos Olímpicos, aunque movilizando un número largamente superior de asistentes, si se toma en consideración su tiempo de duración.

Aunque es evidente su relevancia internacional, el Perú no acudió en 2015. Había participado auspiciosamente en ocasiones anteriores, pero también estuvo ausente en otras. Fue el único país de América del Sur en no asistir a aquella importante cita. La decisión del Estado peruano de no participar fue motivo de duras críticas, sin duda justificadas. Se adujo como razón principal los altos costos que demandaba la construcción y habilitación del espacio (pabellón) que cada país requiere instalar a fin de albergar a los productos nacionales.

La prensa escrita limeña fue eficaz caja de resonancia para endurecer las críticas a una tan poco meditada decisión del Gobierno. Sin embargo, cabe aclarar que las críticas se centraron apenas en un aspecto específico: la no participación de la pujante y exitosa gastronomía peruana en un evento internacional de alta visibilidad. No obstante, y sin restar merecimiento alguno a tan plausible objeto, al quedar las críticas circunscritas a ese solo aspecto, estas omitían la razón central por la que un país evalúa participar en un evento de esa naturaleza: proyectar una imagen múltiple con la que muestre su singularidad cultural, pero de igual manera aquellos aspectos que comparte con otros países de la comunidad internacional. Unnación país no participa en una feria internacional para promocionarse en un solo aspecto, sino para dar una imagen que lo torne atractivo como una totalidad.

La situación descrita permite plantear dos interrogantes esenciales. Primero: ¿desde cuándo se vienen celebrando encuentros de tal importancia? Segundo: ¿fue la de 2015 la 
primera vez que el Perú no acudía a una feria internacional? Como se afirmó al inicio de este texto, las Exposiciones Internacionales, se organizaron en Europa desde mediados del siglo xix. Ya en su primera convocatoria en Londres en 1851, cada país organizador debía convocar a la mayor cantidad posible de países participantes, los que a su vez reunían un número variable de productores de distintos sectores económicos, a los que se proponía seleccionar sus productos más emblemáticos con el objetivo de exhibirlos ante un público masivo que acudiría, entusiasta, a un evento de relevancia internacional. El gráfico 1, abajo, muestra los 32 certámenes organizados desde 1851 hasta la actualidad. Se consignan los países sedes, los países participantes y el volumen de público asistente.

Gráfico 1. Exposiciones universales (siglos XIX-XXI): sedes, países participantes y número de visitantes

\begin{tabular}{|c|c|c|}
\hline Exposición & Países & Visitantes \\
\hline 1851 Londres & 26 & 6000000 \\
\hline 1855 París & 27 & 5100000 \\
\hline 1862 Londres & 39 & 6000000 \\
\hline 1867 París & 42 & 15000000 \\
\hline 1873 Viena & 35 & 7200000 \\
\hline 1876 Filadelfia & 35 & 10000000 \\
\hline 1878 París & 35 & 16100000 \\
\hline 1880 Melbourne & 33 & 1300000 \\
\hline 1888 Barcelona & 30 & 2300000 \\
\hline 1889 París & 35 & 32500000 \\
\hline 1893 Chicago & 19 & 22000000 \\
\hline 1897 Bruselas & 27 & 6000000 \\
\hline 1900 París & 40 & 50800000 \\
\hline 1904 Saint Louis & 60 & 19600000 \\
\hline 1905 Lieja & 35 & 7000000 \\
\hline 1906 Milán & 40 & $s / d$ \\
\hline 1913 Gante & 24 & 9500000 \\
\hline 1915 San Francisco & 24 & 18800000 \\
\hline 1929 Barcelona & 29 & 5800000 \\
\hline 1933 Chicago & 21 & 38800000 \\
\hline 1935 Bruselas & 35 & 20000000 \\
\hline 1937 París & 45 & 31000000 \\
\hline 1939 Nueva York & 54 & $s / d$ \\
\hline 1949 Puerto Príncipe & 15 & 250000 \\
\hline 1958 Bruselas & 39 & 41400000 \\
\hline 1962 Seattle & 49 & 9800000 \\
\hline 1967 Montreal & 62 & 50300000 \\
\hline 1970 Osaka & 78 & 64200000 \\
\hline 1992 Sevilla & 108 & 41800000 \\
\hline 2000 Hannover & 155 & 18100000 \\
\hline 2010 Shanghái & $246^{*}$ & 73100000 \\
\hline 2015 Milán & 145 & 21500000 \\
\hline
\end{tabular}

* La cifra es la que aparece. Nos ha llamado la atención el número de países participantes. Hemos redondeado las cifras del número de visitantes a cada evento.
Un total de doce exposiciones se llevaron a cabo entre 1851 y 1897, y fueron celebradas en tres continentes. Europa llevó la delantera con nueve eventos; le siguió América, con dos; y luego Oceanía, con uno. La ciudad que más veces organizó fue París, en un total de cuatro ocasiones, seguida de Londres, en dos; mientras que Viena (1873), Barcelona (1888) y Bruselas (1897) lo hicieron en una sola ocasión. Filadelfia (1876) y Chicago (1893) representaron a América; Melbourne (1880), a Oceanía. De acuerdo con la revisión preliminar ndimos, la d bibliografía desarrollada alrededor del tema es muy amplia (Goehlert, 2005). Una perspectiva ya clásica, centrada en el desarrollo de la idea de exposición y de sus dimensiones culturales, aún sigue siendo referencia de consulta obligatoria (Plum, 1977). En los dos siglos siguientes, de 1900 en adelante, Europa mantuvo la primacía con once eventos, frente a los siete de América y los dos de Asia (Goehlert, 2005).

El crecimiento urbano que registró París en la segunda mitad del siglo xix probablemente explique el éxito en la convocatoria tanto de países participantes como de público asistente. En tal época, esa ciudad representaba la materialización misma de la modernización, y el avance de los servicios - en transporte y en abastecimiento moderno de agua - encarnaba a escala urbana el progreso (Glaeser, 2011). Además debe considerarse el hecho no menor de que las ciudades sede de exposiciones habían alcanzado logros importantes a escala industrial; en tal virtud, y aunque no alcanzó la envergadura de la industria inglesa, la de Francia se encontraba más diversificada que aquella (Zamagni, 2011).

Estos eventos, en tanto encuentros globales, organizan actividades simultáneas en las que se conjugan reuniones de distinta índole que van desde exposiciones hasta reuniones de negocios y debates. Para la institución encargada de organizarlos, el BIE, existen cuatro razones esenciales asociadas a cada uno de los diferentes actores que acuden al evento; para la comunidad internacional, una EXPO representa una plataforma para alentar el progreso y la cooperación; para el público en general, se trata de una relevante experiencia educativa y entretenida; y para el país anfitrión es una herramienta para su promoción y desarrollo. Finalmente, para los participantes, los grandes animadores de la reunión, una EXPO ofrece grandes oportunidades de negocio, gracias a la enorme visibilidad que tienen los productos materia de exposición (Bureau International des Expositions, s. f.-b). Puede afirmarse que estas exposiciones representan una de las expresiones más visibles y materiales del proceso de globalización.

El tema que involucraba la primera pregunta nos pareció relevante porque dichos eventos se vienen realizando hasta la actualidad, con periodicidad variable, influido esto por diversas coyunturas internacionales (como fue el caso de las dos guerras mundiales, que alteraron sus convocatorias) y también porque en el tiempo han surgido nuevas modalidades, en particular aquellas dedicadas 
a productos alimentarios ${ }^{1}$. Desde la racionalidad de los expositores participantes, existe un afán legítimo: concurrir a certámenes internacionales es una ocasión única para alcanzar un objetivo estratégico para sus negocios; esto es, el recibir un premio por la calidad de los productos que exhibe y que se materializa con una medalla que luego servirá de base para la promoción comercial del producto. Los propios organizadores de los certámenes anuncian explícitamente el propósito de sus eventos; para ellos, una medalla recibida es "una herramienta de venta. Una medalla [...] puede aumentar sus ventas y abrirles nuevos mercados de exportación [...] Una medalla es una herramienta comercial que aumenta las ventas en más de un 20\%" (Concours Mondial de Bruxelles, s. f.-b)".

Entendemos, entonces, que una medalla o un diploma representa un componente gravitante dentro de la estrategia mayor de marketing de la empresa. Es, además, un claro indicador de la calidad del producto, pues demuestra que ha logrado imponerse frente a decenas de ellos provenientes de todo el mundo, y todos de altas calidades (condición indispensable para la participación). Una vez obtenida, la medalla se convierte en un poderoso motor de promoción del producto, ya que la empresa la empleará de modos diversos, entre ellos, a modo de elemento de identificación en los documentos destinados a la clientela (Agence pour la Valorisation des Produits Agricoles, s. f.;. Como resulta previsible, algunas compañías peruanas consideran ello un elemento central en su posicionamiento, y llevan al efecto una cuenta exhaustiva de su participación en concursos internacionales (Tacama, s. f.-b), remontando incluso sus logros hasta mediados del siglo xix (Tacama, s. f.-a). En consecuencia, participar en un encuentro internacional es parte de las estrategias de comercialización implementadas por las empresas en pos de legitimar la calidad de su producto a través de un poderoso mecanismo de comparación con otros similares.

No obstante, creemos que una diferencia sustancial entre las antiguas performances desarrolladas en las EXPO y las actuales radica en el hecho de que, en el pasado, la participación de cada país se sostenía principalmente en la presencia de empresarios, esencialmente productores de bienes, que acudían con el fin de recibir una medalla que apuntalase su proceso de legitimación de calidad de producto. La participación del país se daba de manera oficial desde el momento en que el Estado recibía una invitación formal, para luego iniciar una convocatoria a lo largo del país, llamando a los productores que desearan formar parte de ese evento. Por el contrario, en la actualidad los países participan de manera más integral, proponiendo, más bien, consolidar una imagen amplia del país en lugar de una serie de performances individuales. Es el país el que recibe una premiación directa. Tal fue el caso de los Estados sudamericanos

1. Paralelamente a la existencia de las Expo, y también como eventos con décadas de realización, se celebran concursos internacionales dedicados a productos específicos. Tal es el caso del Concours Mondial de Bruxelles para productos vitivinícolas. Para el café, existe la Specialty Coffee Association of America (SCAA) a los que se premió por la conceptualización con la que fueron concebidos los pabellones que albergaron la amplia gama de productos con los que se presentaban ante el mundo (Gobierno de Chile, 2016). Su participación fue el resultado de una eficaz asociación público-privada, gestada con mucha anticipación, más allá del inicio de la EXPO.

No hemos identificado el momento en que las exposiciones internacionales dejaron de otorgar premios en específico a los empresarios. Pareciera que el afán de recibir reconocimientos, entendibles y necesarios para sus propósitos de posicionamiento de marca, se trasladó a los concursos internacionales que se centraron en un producto en particular. En el caso de los productos vitivinícolas, en eventos que se organizaron desde mediados de la década de $1990^{2}$.

No es el propósito del presente análisis indagar y discutir las diversas responsabilidades que les cupo asumir a las distintas instancias del Estado peruano frente a la participación del país en dichos encuentros. Más bien, nos interesa centrarnos en desarrollar la segunda interrogante, anteriormente planteada, aportar información de primera mano y abrir nuevos rumbos de investigación.

¿Por qué el Perú no participó en Milán 2015? Esta es la segunda pregunta, para cuya respuesta no contamos aún con un panorama exhaustivo. Su resolución es parte de una investigación de más largo aliento. Una importante contribución al tema pasó revista, hace unos años, a la participación peruana en las primeras EXPO (Quiñones, 2007). En ella se muestra, por ejemplo, el contraste visible entre la auspiciosa presencia del Perú en la EXPO de Filadelfia en 1876 frente a su inasistencia a la de Chicago de 1893, a pesar de que se contaba con la invitación oficial de los organizadores. Se perdió así una oportunidad única para favorecer el proceso de reconstrucción nacional, tras la debacle sufrida durante la guerra del Pacífico (Quiñones, 2007, pp. 166, 230). A la luz del segundo caso, cabe preguntarse si existe quizá alguna gran diferencia entre las decisiones adoptadas por el Estado peruano para justificar la ausencia de 1893 y la de 2015. La respuesta es la siguiente: ninguna, pues en ambas circunstancias se adujo falta de fondos, lo cual vendría a revelar más bien la miopía de los funcionarios del Gobierno de turno ante los potenciales beneficios de mediano plazo que la participación en los eventos conllevaría. Uno aquí no puede sino preguntarse cómo, tras más de 120 años, puede un Estado incurrir en el mismo error.

Trabajos de más cercana data se han centrado en la participación peruana en algunos eventos de la segunda mitad del siglo xix (Londres, 1851; Filadelfia, 1876; París, 1878; París, 1889; y Chicago, 1893) (Quiñones, 2007, pp. 138 y ss.). No sabemos aún cuál fue la performance en los siete encuentros restantes. La consulta de información de primera mano nos ha revelado un panorama interesante: de

2. Dos de los principales concursos iniciaron sus actividades en 1994: Vinalies Internationales y el Concours Mondial de Bruxelles. 
entre los productos premiados en la Exposición de París de 1900, algunos fueron otorgados a empresarios peruanos ${ }^{3}$. Debe considerarse el hecho de que en la organización de certámenes tan masivos se requería, con carácter de indispensable, agrupar los productos de acuerdo con diferentes categorías, denominadas grupos, que estaban subdivididas a su vez en clases. Con el afán de saber cuál fue el verdadero logro de cada empresario peruano, consideramos precisar la cantidad de medallas otorgadas en cada clase y de cada tipo (oro, plata y bronce), hallando así la identidad de los empresarios ganadores. En cada clase se repartían centenas de medallas. Por ejemplo, en el caso de las medallas de oro, sabemos que se concedían cien ejemplares a sendas empresas. Por ello, cabría preguntarse cuán destacado era un producto receptor de una medalla de tal o cual tipo, cuando muchos otros habían sido favorecidos con similar reconocimiento.

Los empresarios que participaban en calidad de expositores en alguna de las diversas muestras que conformaban el evento mostraban sus productos en stands adecuadamente habilitados y compartidos con lo exhibido por los demás países del mundo. La mejor performance empresarial peruana se registró en las clases 12 y 62, dedicada la última a la producción de bebidas, que incluían cerveza y aguas carbonatadas (las hoy llamadas gaseosas). La cervecería Backus y Johnston, fundada en 1879, se hizo merecedora de una medalla de oro, que sirvió muchos años como elemento central en la publicidad de la empresa para las páginas de la prensa limeña ${ }^{4}$

La concesión de una medalla era el reconocimiento al indudable mérito alcanzado por el producto. Ello quedaba consignado en la fundamentación que alcanzaba el jurado reunido a tal efecto, conformado por representantes de varios países. Sin embargo, debe entenderse que dicha concesión también la recibían otros productores. En el caso del grupo en el que participó Backus y Johnston, cien medallas de oro se otorgaron en el rubro de bebidas, la mayor parte concedidas a países europeos, especialmente Francia y Bélgica. América Latina estuvo presente en el reconocimiento final apenas con seis medallas: cuatro para México, y, para el Perú y Ecuador, una respectivamente (Liste des récompenses, 1901, pp. 741 y ss.). Ello significa que, en este rubro manufacturero, América Latina reunió apenas el $6 \%$ del total de medallas de oro otorgadas.

El texto que presentamos corresponde a una indagación preliminar que intenta introducir un componente temporal en el análisis de las estrategias empresariales peruanas. A partir de una revisión bibliográfica, se ha

3. Los empresarios premiados en la Exposición Universal de 1900 fueron, dentro del grupo III, clase 12 (de fotografía), Eugène Courret, con una medalla de oro; clase 13 (de librerías), cinco medallas, esto es: dos de plata, para el Ateneo de Lima y la Sociedad de Geografía de Lima, y tres de bronce, para la Librería e Imprenta Gil, Primitivo Sanmarti y Guillermo Stolte (Ministère du Commerce, de l'industrie, des postes et des télégraphes du République Francaise, 1901).

4. Hemos hallado publicidad inserta en diarios de Lima donde The Backus \& Johnston Brewery Co. Ltd. se presenta como la única fábrica cervecera, "premiada con la única medalla de oro en el Perú", alusión inequívoca al premio recibido en París de 1900. querido fundamentar unas observaciones iniciales con el propósito de apreciar cuál es el rol que la información histórica cumple en la identificación de la implementación de las estrategias comerciales, tanto en el Perú como en el exterior, durante esta primera globalización.

Retomando las dos interrogantes iniciales, cabría preguntarse adicionalmente si las alusiones históricas de las que hace uso una empresa son decisivas en el momento en que se produce el acto de compra del producto por parte del consumidor. Algunas empresas de renombre internacional las siguen empleando, aunque se sostengan en premios recibidos en el pasado 5 . ¿Juegan a favor o en contra las alusiones históricas de las que se vale una empresa como parte de su estrategia comercial? ¿O el consumidor es sencillamente indiferente ante ellas? Nos parece fundamental entender también por qué hay otras compañías, antiguas, que no requieren de alusiones a su pasado o al de alguno de sus productos. ¿Se trata de decisiones que recaen únicamente en instancias directivas superiores? Pareciera ser cierto - aunque afirmarlo categóricamente no sería prudente-- que cualquier alusión histórica per se no sería suficiente para estimular una decisión de compra: requeriría complementarse con otros elementos, como el precio, la sensación de estatus, la calidad intrínseca del producto o del servicio o, como lo dictan las nuevas tendencias de consumo, si la empresa muestra una performance social o ecológicamente responsable.

Pensar las marcas desde una perspectiva histórica es útil, pues ayuda a identificar uno de los varios componentes que definen el acto de consumo, sostenido en variables profundamente emocionales. Se ha afirmado que tomamos el 85\% de nuestras decisiones de compra por la vía de la emoción, razón por la que se recomienda que los líderes de las organizaciones trabajen intensamente para estimular dicha compra a través de mecanismos eficaces, como la comunicación y el lenguaje positivo (Foro de Marcas Renombradas Españolas, 2016). Las marcas forman parte de la vida de sus consumidores; se potencian gracias a la fidelidad de sus clientes y a la calidad del trabajo que el personal de la empresa, en todas sus diversas instancias y jerarquías, le imprime a la producción y exhibición de los productos. Son, además, parte esencial del valor de cada compañía, pues forman parte importante de sus activos (Backus, 2014). Algunas experiencias estatales perfilan un horizonte ideal para la expansión y la consolidación de marcas peruanas en el exterior; tal es el caso del Foro de Marcas Renombradas de España, una alianza estratégica público-privada entre el Estado español y las principales marcas de proyección internacional, con el objetivo de posicionar la imagen del país y, de manera más directa, expandir los negocios españoles a escala internacional, pero con una cobertura amplia e institucional (Foro de Marcas Renombradas Españolas, s. f.).

No hay duda de que las exposiciones internacionales son parte de ese intento por mostrar la enorme variedad de recursos de países que recién empezaban a conocerse entre sí, pero, además de ello, significan en la práctica una

5. Ver el caso del ron Bacardi (Bacardi Limited, s. f.). 
suerte de "ventanas del progreso", pues son la vía ideal para mostrarse y observar simultáneamente el comportamiento del comercio, la tecnología, la ciencia y demás áreas. Las exposiciones internacionales se desarrollaron coincidiendo con un momento en el que se produjo la expansión del comercio mundial (Kenwood \& Lougheed, 1995; Zamagni, 2011), asociado a las profundas transformaciones en el ámbito de los transportes y las comunicaciones (Hobsbawm, 1998); y son parte de la expansión conjunta del capitalismo financiero y del industrial (Frieden, 2013; Cameron \& Neal, 2014), proceso que influyó decisivamente para establecer más hondas diferencias de crecimiento y desarrollo entre las áreas denominadas por la escuela de pensamiento "dependista" como centro y periferia, haciéndose más visible lo que algunos han denominado la gran divergencia (Williamson, 2012).

Si un evento de índole tan trascendental como una feria internacional tiene tanta resonancia para efectos de posicionamiento de una imagen nacional, se desprende entonces que la participación que el país haga debería revelar una política definida por el Estado, y no ser solo resultado de decisiones coyunturales. Por ello, se hace indispensable saber cuál ha sido el camino recorrido en las relaciones Estado-empresariado en materia de visibilización comercial, y si pueden hallarse en el pasado antecedentes de políticas comerciales, como las que hoy en día se reflejan en el Plan Estratégico Nacional Exportador (PENX) 2016-2025. Tener una imagen completa de la participación peruana en las exposiciones internacionales es una vía que hace falta transitar.

\section{REFERENCIAS}

Agence pour la Valorisation des Produits Agricoles. (s. f.). Las medallas del concurso AVPA. Recuperado de http://www.avpaoleo.com/es/las-medallas-delconcurso-avpa/

Bacardi Limited. (s. f.). Recuperado de https://www. bacardilimited.com/

Bureau International des Expositions. (s. f.-a). Expo Timeline. Recuperado de http://www.bie-paris.org/site/ en/expo-timeline

Bureau International des Expositions. (s. f.-b). What is an Expo? Recuperado de http://www.bie-paris.org/site/en/ expos/about-expos/what-is-an-expo

Cameron, R. \& Neal, L. (2014). Historia económica mundial. Desde el Paleolítico hasta el presente. Cuarta edición. Madrid: Alianza Editorial.

Concours Mondial de Bruxelles. (s. f.-a). Concours Mondial de Bruxelles. Recuperado de http://www. concoursmondial.com/es/el-concours-mondial-debruxelles/

Concours Mondial de Bruxelles. (s. f.-b). Por qué participar. Recuperado de http://www.concoursmondial.com/es/ por-que-participar/
Expo Milano 2015. (s. f.). Rivivi l'esperienza dell'Esposizione Universale. Recuperado de http://www.expo2015.org/ rivivi-expo/

Fleischmann. (s. f.). Historia. Recuperado de http:// fleischmannperu.pe/Nosotros/Historia

Foro de Marcas Renombradas Españolas. (s. f.). Presentación y Objetivos. Recuperado de http://www. marcasrenombradas.com/foro-de-marcas/presentaciony-objetivos/

Foro de Marcas Renombradas Españolas. (2016). Memoria de actividades 2015. Madrid: Autor.

Frieden, J. (2013). Capitalismo global. Madrid: Cátedra.

Glaeser, E. (2011). El triunfo de las ciudades. México D. F.:Taurus.

Gobierno de Chile. (2016). Expo Milán. Memoria del pabellón de Chile. Santiago de Chile: Autor.

Goehlert, R. (2005). World's Fairs: A Guide to Selected English-Language Resources. Bloomington: Indiana University, Center for the Study of Global Change.

Hobsbawm, E. (1998). La era del imperio, 1875-1914. Buenos Aires: Crítica.

Juglar, P. (s. f.). El mercado del café estará listo para recibir los cafés tostados al origen. Recuperado de http://www. avpacafe.com/el-mercado-del-caf--estar--listo-pararecibir-los-caf-s-tostados-al-origen-html

Kenwood, A. G. \& Lougheed, A. L. (1995). Historia del desarrollo económico internacional. Madrid, Istmo.

Backus y Johnston. (2015). Memoria anual 2014. Recuperado de http://backus.pe/pdf/Memoria-Anual-2014-Backus.pdf

Ministère du Commerce, de l'industrie, des postes et des télégraphes du République Francaise. (1901). Liste des Récompenses. Exposition Universelle de 1900. À Paris. 1901. Recuperado de http://gallica.bnf.fr/ark:/12148/ bpt6k9765409t/f9.item.r=p\%C3\%A9rou

Plum, W. (1977). Exposiciones mundiales en el siglo XIX, espectáculos del cambio socio-cultural. Aspectos sociales y culturales de la industrialización. Bonn: Fundación Friedrich Ebert.

Quiñones Tinoco, L. (2007). El Perú en la vitrina. El progreso material a través de las exposiciones (1851-1893). Lima: Proyecto Historia UNI.

Tacama. (s. f.-a). Historia. Recuperado de http://tacama.com/ historia.html

Tacama. (s. f.-b). Premios. Recuperado de http://tacama.com/ premios.php

Vinalies Internationales. (s. f.). Recuperado de https:// vinalies-internationales.com/fr/

Williamson, J. (2012): Comercio y pobreza; cuándo y cómo comenzó el atraso del tercer mundo. Barcelona: Crítica.

Zamagni, V. (2011). Historia económica de la Europa contemporánea; de la revolución industrial a la integración europea. Barcelona: Crítica. 